\title{
Is it possible to sort the disability of individuals with migraine based on the International Classification of Functioning, Disability and Health? A Scoping Review
}

\author{
Hugo Feitosa (D), Débora Wanderley (D), Manuella Morais Monteiro Barbosa Barros (D), Suellen Freitas da Silva (iD), \\ Alyne Karine de Lima Santos (iD , Angélica da Silva Tenório (iD , Daniella Araújo de Oliveira (iD)
}

${ }^{1}$ Universidade Federal de Pernambuco, Recife, Brazil.

\section{$凶$}

Hugo Gabriel Feitosa de Souza, Department of Physical Therapy, Federal University of Pernambuco, Av. Jorn. Aníbal Fernandes, 173 Cidade Universitária, Zip Code: 50740-560, Recife -PE.

Phone: + 55 (81) 2126.8937.

E-mail: hugogfeitosa@gmail.com

Edited by:

Marcelo Moraes Valença

\section{Keywords:}

International Classification of Functioning

Disability and Health

Sickness Impact Profile

Environmental Health

Migraine disorders

Disabled Persons

\begin{abstract}
Purpose

To identify the most frequent outcomes related to disability assessed in individuals with migraine and to correlate these findings with the categories of International Classification of Functioning, Disability and Health.

Material and method

This scoping review was developed based on studies with adult population (18-55 years) of both sexes and assessing the disability generated by migraine. We included studies in which patients had a diagnosis of migraine based on International Classification of Headache Disorders.

Results

52 articles were found with 42 outcomes related to 17 categories of International Classification of Functioning, Disability and Health, including the four main components of the classification, with seven categories in "Body Functions", one in "Body Structures", four in "Activities and Participation" and five in "Environmental Factors".

\section{Conclusion}

The findings show that disabilities, activity limitation, or participation restriction generated by migraine can be classified by International Classification of Functioning, Disability and Health. The components "body functions", "environmental factors" and "activities and participation" were the most identified in the present study. Thus, this classification is important to classify the disability caused by migraine and to guide a rehabilitation more focused on the patient's real demands, as well as directing the research involving this population.
\end{abstract}




\section{Introduction}

$M$ igraine is the third-most prevalent disease in the world and the second one to cause larger numbers of lost work days due to a disability. ${ }^{1}$ Sleep disorders, decrease in the perception of quality of life and the well-being sensation and increase in anxiety crises have been related to migraine crises, in addition to the influence in social function due to disability and decreasing social status caused by this condition. ${ }^{2-5}$

In this way, there are severe impacts of migraine on the quality of life and social function of the affected individuals, which makes this illness affect a wider spectrum as it generates psychological and social problems for both the affected individual and the social environment to which he belongs to either for the greater difficulty in maintaining social relations or even for the economic impacts caused by the reduced productivity of migraineurs. ${ }^{1,4,6}$

Because migraine is a disease that causes negative impacts that go beyond biomedical issues, the World Health Organization (WHO) instituted the International Classification of Functioning, Disability and Health (ICF), whose classification model seeks to obtain a broader view of the health-disease process. Thus, it is important to assess migrants in a broader perspective that covers physical, emotional, psychological, functional, social and environmental conditions. ${ }^{6,7}$

Despite the exposed, there is a gap in literature about biopsychological issues generated by migraine that have undeniable implications on the patients' functioning. Therefore, the application of ICF is a way to classify the functioning of this population, since this proposal focuses on the patient's approach on this broader vision as adopted by the WHO.6,7

Therefore, the present study aimed to conduct as coping review to map the most important implications of migraine in a patient's functioning from the main disabilities presented by this population in the past studies.

\section{Material and Methods}

It's a scoping review recorded on Open Science Framework.

\section{Design}

In as coping review, the methodology seeks to map the determined subject through a systematized starting point, including summarization and analytical review of published texts. ${ }^{8,9}$ As coping review proposal is to search for information regarding the selected process, which frequently demands that diverse outcomes be used. Thus, such review can act as a tool for conducting systematic reviews as suggested by past data. ${ }^{10}$ The standard model, as proposed by Joanna Briggs Institute Manual, suggests the following: 1. Creation of title, aim, and conductor question to be answered;2. Choice of sources and search for data chain are followed by study selection and data extraction; and 3. Presentation of results and practical implications.

It is important to highlight that, in the study selection, as proposed by the Joanna Briggs Institute guide, inclusion and exclusion criteria were applied, based on the population, context, and concept, with the aim of responding to the conductor question of "what are the disabilities related to adult patients with migraine?"

\section{Inclusion Criteria Population}

Adults (18-55 years) of both the sexes were included in this review, considering that migraine affects different age groups and also this age group represents the higher prevalence range. $^{2}$

\section{Concept}

Disability has been the searched concept defined by WHO as a term that includes deficiencies (related to functions and structures), limitations (joined to performed) activities, and restrictions (related to social participation) as well as environmental factors interacting with these constructs. ${ }^{11}$

\section{Context}

Studies that assessed patients with a prior diagnosis of migraine were included, as per the International Classification of Headache Disorders (ICHD) Versions I2, $\mathrm{II}^{12}$, III-Beta ${ }^{13}$, with the objective of broadening the impact spectrum of migraine patients included in hospitals, outpatient clinics, specialized centers for headaches, or in their own communities.

\section{Study Selection}

The searches were conducted from November 2017 to June 2018 and updated on June 2020, by a trained personal in the following databases: Medine/Pubmed, 
Lilacs, Cinahl, Scopus (Elsevier) Web of Science, and Cochrane Database of Systematic Reviews, by using indexed descriptors and keywords, without restriction of year of publication, language or study design.

\section{Research Strategies}

In the databases Medline, Scopus (Elsevier) Web of Science, and Cochrane Database of Systematic Reviews, we considered the following descriptors of the Medical Subject Headings (MeSH): "Migraine Disorders", "Disability Evaluation", "Quality of Life", and the keyword "Functioning". For a Lilacs basis, we considered the descriptors in Health Sciences (Migraine Disorders), Quality of Life, Disability Assessment, and a keyword "Functioning". From the database Cinahl, we used the terms of its titles: "Migraine", "Disability Assessment", "Quality of life", "International Classification of Functioning" "Disability AND Health" AND "Functioning".

The Boolean operator "AND" was used to cross the descriptors by defining the search strategy (Figure 1).

\section{Primary Identification of the Articles}

Initially, the studies shortlisted from the search strategies were identified by title and abstract and summarized so that two independent researchers could judge whether they were relevant to answer the conducting question. In case of a disagreement, a third researcher would be activated to assist in clarifying doubts and taking a final decision about the relevance of the article. In cases where, even after taking these measures, the article relevance was still considered dubious, it would be included for the reading phase of the full text for deeper clarification. Next, those articles that met the inclusion criteria and could adequately answer the guiding question were finally included in the study.

\section{Data Extraction}

For this phase, a spreadsheet was created in the Microsoft Excel Program to be filled with each study data. The ones collected from each study included: article title, authors' names, publication date, diagnostic criteria, population's age range, main study outcomes, and tools used for this aim.

We then organized a table with these data by relating the outcomes found with the equivalent ICF categories in the sense of identifying the ones that were more relevant for the assessment of patients with migraine.

\section{Results}

Figure 2 shows the capitation flowchart of articles in this review. In the initial search, 2,567 articles were found, of which 979 were repeated between databases, 889 were excluded after reading their titles or abstracts, and 698 articles were considered relevant for reading the text.

After the complete reading of the articles, 584 of them were excluded because they did not meet the inclusion criteria or for being considered irrelevant for the study. With this proceeding only 114 were taken to the phase of data extraction. In these 114 articles, we have identified that 60 studies used exclusively the result of validated questionnaires for patients with migraine: Migraine Disability Assessment (MIDAS), Headache Impact Test-6 (HIT-6) e Migraine-Specific Quality of Life Questionnaire (MSQ). For recognizing the importance of such questionnaires in the assessment of patients with migraine, these studies were considered relevant and included in this review. However, at the moment of data extraction, it was not possible to identify what functional aspects of the patients were affected, since the presentation of results of these studies did not permit to identify which categories were more relevant in this population. Because of this, just the 52 remaining articles had their data extracted, tabulated and categorized in our study.

\section{Description of Articles}

The 54 articles included in this review were published in 17 different countries, involving 13,383 patients, with a mean age of 38.7 years, of whom 9,621 were women, 3,762 men and 2,264 were not identified in relation to sex in the studies. As for the publishing location, it is possible to highlight the United States as the place with larger number of publications. These studies were published in the interview from 1994 up to 2019, being 2012 the year that presented the largest number of publications of the articles included in this research (Table 1).

The study design most found in this study was randomized clinical trial (23 articles), followed by cross-sectional studies (13 articles), literature reviews, and then other types of study (such as cohort, systematic review, control-case, and qualitative), totaling 9 articles.

Table 2 shows the outcomes found in this scoping review and the ICF-correlated categories. The assessed outcomes in these articles were related to 17 ICF categories, of which seven were for the components "Body Functions", one for 


\begin{tabular}{|c|l|}
\hline \multirow{4}{*}{ MEDLINE/Pubmed } & \#1 ("Migraine Disorders"[Mesh]) AND ("Disability Evaluation"[Mesh]) \\
\#2 ("Migraine Disorders"[Mesh]) AND ("Quality of Life"[ Mesh]) \\
\#3 ("Migraine Disorders"[Mesh]) AND ("Functioning") \\
\#4 ("Migraine Disorders"[Mesh]) AND "Cost of Illness"[Mesh]
\end{tabular}

Figure 1. Search strategies for MEDLINE/ Pubmed, Lilacs, Cinahl, Cochrane Database of Systematic Reviews and Scopus (Elsvier) databases. 


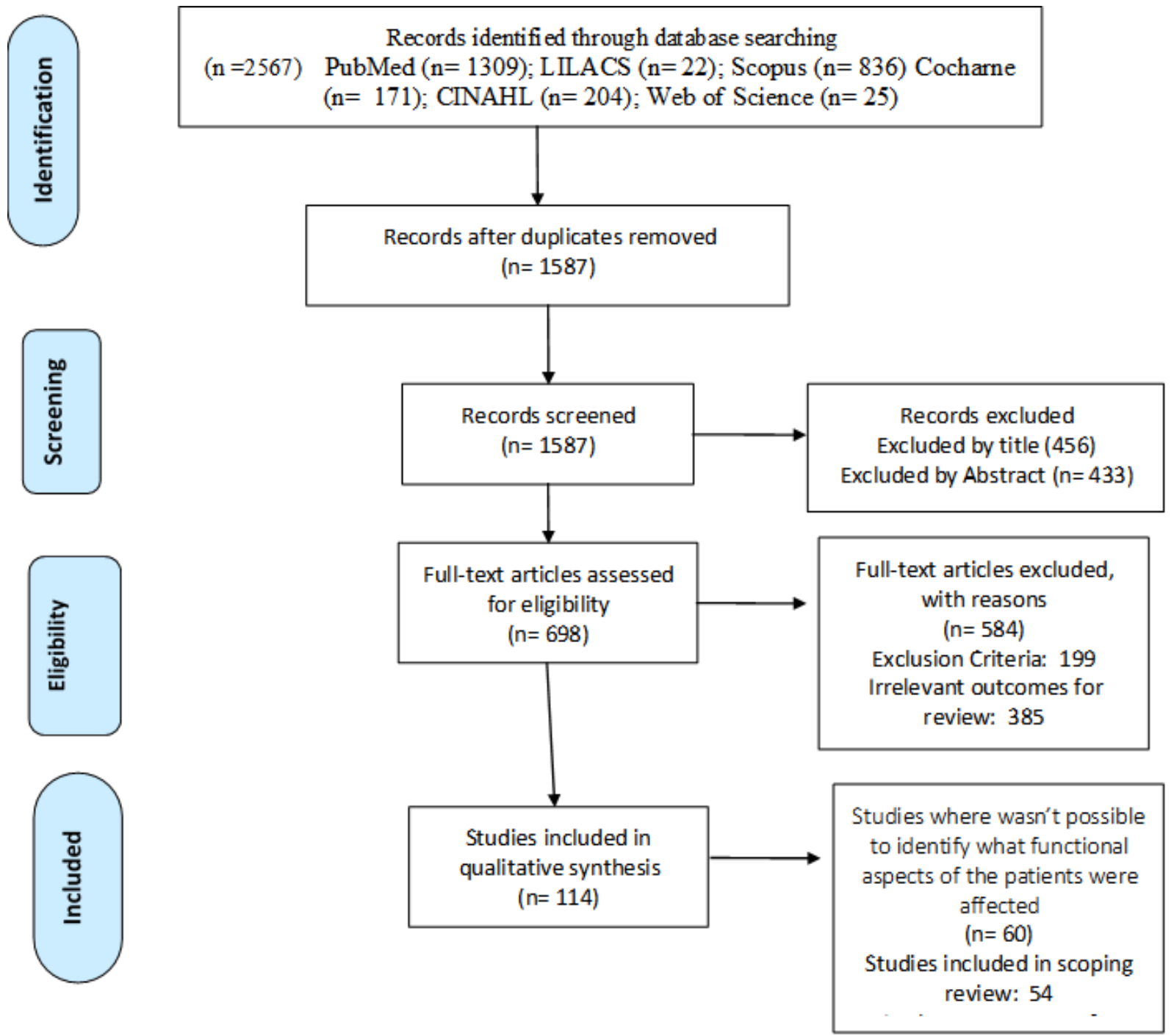

Figure 2. Preferred Reporting Items for Systematic Reviews and Meta-Analyses flow diagram of included articles. 
Table 1. Characteristics of studies included in the scoping review $(n=54)$.

\begin{tabular}{|c|c|c|c|c|c|c|c|}
\hline Period & Country & Study Design & n & Period & Country & Study Design & $\mathbf{n}$ \\
\hline \multirow{11}{*}{$2013-2020$} & Italy & $\mathrm{RCT}$ & 1 & (2001 2001 & Romil & Crocerection atude & 2 \\
\hline & Turkey & RCT & 1 & $2001-2004$ & Brazil & Cross-sectional study & 2 \\
\hline & & Cross-sectional study & 1 & & USA & Literature review & 1 \\
\hline & China & Systematic review & 1 & & & Case-control study & 1 \\
\hline & Philippines & Cross-sectional study & 1 & & & Cross-sectional study & 1 \\
\hline & Brazil & Cross-sectional study & 2 & & & Longitudinal study & 1 \\
\hline & Iran & RCT & 1 & & France & RCT & 1 \\
\hline & USA & Literature review & 1 & & Turkey & RCT & 1 \\
\hline & & RCT & 2 & & Germany & RCT & 1 \\
\hline & Spain & Systematic review & 1 & $1997-2000$ & USA & RCT & 1 \\
\hline & Netherlands & RCT & 1 & & & Literature review & 1 \\
\hline \multirow[t]{7}{*}{ 2009-2012 } & USA & RCT & 6 & & France & Cohort study & 2 \\
\hline & Brazil & $\mathrm{RCT}$ & 1 & & England & Cross-sectional study & 1 \\
\hline & Thailand & RCT & 1 & 1994-1996 & USA & RCT & 1 \\
\hline & Taiwan & Cross-sectional study & 1 & & Netherlands & Cross-sectional study & 1 \\
\hline & Switzerland & Observational study & 1 & & USA & RCT & 1 \\
\hline & China & RCT & 1 & & India & RCT & 1 \\
\hline & Iran & Case-control study & 1 & & & & \\
\hline \multirow[t]{8}{*}{$2005-2008$} & USA & RCT & 2 & & & & \\
\hline & & Case series study & 2 & & & & \\
\hline & & Observational study & 1 & & & & \\
\hline & & Literature review & 1 & & & & \\
\hline & & Qualitative study & 1 & & & & \\
\hline & Norway & Literature review & 1 & & & & \\
\hline & Taiwan & Cross-sectional study & 1 & & & & \\
\hline & France & RCT & 1 & & & & \\
\hline
\end{tabular}

Note. RCT: Randomized Clinical Trial 
Table 2. Outcomes evaluated in studies included, related to International Classification of Functioning, Disability and Health categories and its description $(\mathrm{n}=42)$.

\begin{tabular}{|c|c|c|}
\hline Outcomes Found/ Tools & Related Category & Description \\
\hline \multicolumn{3}{|l|}{ Body functions } \\
\hline $\begin{array}{l}\text { Frequency of pain, intensity of pain/ Headache diary, } \\
\text { Visual analogue Scale }\end{array}$ & b280 Sensation of pain & $\begin{array}{l}\text { Sensation of unpleasant feeling indicating potential or actual damage to } \\
\text { some body structure. }\end{array}$ \\
\hline Energy and vitality/SF-36 & b130 Energy and drive functions & $\begin{array}{l}\text { General mental functions of physiological and psychological mechanisms } \\
\text { that cause the individual to move towards satisfy specific needs and } \\
\text { general goals in a persistent manner. }\end{array}$ \\
\hline $\begin{array}{l}\text { Exercise tolerance, physical activity tolerance, worsens } \\
\text { with physical activity, aggravation with physical } \\
\text { activity, physical performance, vigorous activity/, } \\
\text { qualitative interview, anamnesis, Fatigue Severity } \\
\text { Scale }\end{array}$ & $\begin{array}{l}\text { b4559 Exercise tolerance functions, } \\
\text { unspecified }\end{array}$ & \\
\hline $\begin{array}{l}\text { Nausea and vomiting/ qualitative interview, free } \\
\text { question }\end{array}$ & $\begin{array}{c}\text { b5 } 106 \text { Functions of expelling the } \\
\text { contents of the stomach, oesophagus } \\
\text { or pharynx }\end{array}$ & $\begin{array}{l}\text { Functions of moving substances such as food, liquid, medications, objects } \\
\text { intentionally or unintentionally swallowed in the reverse direction to } \\
\text { ingestion, such as in regurgitation and vomiting. }\end{array}$ \\
\hline $\begin{array}{l}\text { sleepiness, sleep disturbances, to sleep, ability to } \\
\text { sleep/ qualitative interview, Epworth Sleepiness } \\
\text { Scale, Subjective sleep quality was assessed using the } \\
\text { Pittsburgh Sleep Quality Index }\end{array}$ & b134 Sleep functions & $\begin{array}{c}\text { General mental functions of periodic, reversible and selective physical and } \\
\text { mental disengagement from one's immediate environment accompanied by } \\
\text { characteristic physiological changes. }\end{array}$ \\
\hline $\begin{array}{l}\text { Stress, mood, impact on mood, irritability/ } \\
\text { Generalized Anxiety Disorder 7-item scale, Patient } \\
\text { Health Questionnaire 9-item Scale }\end{array}$ & b1263 Psychic stability & $\begin{array}{l}\text { Mental functions that produce a personal disposition that is even-tempered, } \\
\text { calm and composed, as contrasted to being irritable, worried, erratic and } \\
\text { moody. }\end{array}$ \\
\hline Memory/ Fear conditioning test, qualitative interview & b144 Memory functions & $\begin{array}{l}\text { Specific mental functions of registering and storing information and } \\
\text { retrieving it as needed. }\end{array}$ \\
\hline \multicolumn{3}{|l|}{ Body structures } \\
\hline $\begin{array}{l}\text { Head and neck/ Cervical Range of Motion, } \\
\text { algometry, Neck disability index }\end{array}$ & $\begin{array}{l}\text { s710 Structure of head and neck } \\
\text { region }\end{array}$ & \\
\hline \multicolumn{3}{|l|}{ Activities and participation } \\
\hline Leisure and recreation activities & d920 Recreation and leisure & Engaging in any form of play, recreational or leisure. \\
\hline $\begin{array}{l}\text { Social function, social activity, social interactions, } \\
\text { social isolation. }\end{array}$ & d9205 Socializing & $\begin{array}{l}\text { Engaging in informal or casual gatherings with others, such as visiting } \\
\text { friends or relatives or meeting informally in public places. }\end{array}$ \\
\hline $\begin{array}{l}\text { To walk, ability to walk/ qualitative interview, } \\
\text { anamnesis, Fatigue Severity Scale }\end{array}$ & d450 Walking & $\begin{array}{l}\text { Moving along a surface on foot, step by step, so that one foot is always } \\
\text { on the ground, such as when strolling, sauntering, walking forwards, } \\
\text { backwards, or sideways. }\end{array}$ \\
\hline \multicolumn{3}{|l|}{ Environmental factors } \\
\hline $\begin{array}{l}\text { School performance, intellectual performance, school } \\
\text { score, schooldays lost }\end{array}$ & $\begin{array}{l}\text { e5850 Education and training } \\
\text { services }\end{array}$ & $\begin{array}{l}\text { Services and programmes concerned with education and the acquisition, } \\
\text { maintenance and improvement of knowledge, expertise and vocational or } \\
\text { artistic skills, such as those provided for different levels of education }\end{array}$ \\
\hline $\begin{array}{l}\text { Light, strong lights and photophobia/ Headache diary, } \\
\text { anamnesis }\end{array}$ & e240 Light & $\begin{array}{l}\text { Electromagnetic radiation by which things are made visible by either } \\
\text { sunlight or artificial lighting }\end{array}$ \\
\hline $\begin{array}{l}\text { Sound, noise and phonophobia/ Headache diary, } \\
\text { anamnesis }\end{array}$ & e2500 Sound intensity & $\begin{array}{l}\text { Level or volume of auditory phenomenon determined by the amount of } \\
\text { energy being generated, where high energy levels are perceived as loud } \\
\text { sounds and low energy levels as soft sounds. }\end{array}$ \\
\hline
\end{tabular}

Note. b: Body functions; s: Body structures; d: Domains; e: Environment 
"Body Structures", four for "Activities and participation", and five for "Environmental Factors".

In the 60 articles that used some validated questionnaire, but did not present results that could answer this review question, totaled a population of 19,153 people, of which 15,703 were women and 3,273 men with ages 18-55 years (average age: 38.6 years).

\section{Discussion}

The disability classification of patients with migraine can be performed through the ICF, but it is still an uncommonly used instrument in studies developed in this thematic. The validating tools for assessing the migraine impact are unclear in their results about the aspects of life that are more affected, besides being not able to address satisfactorily the biopsychosocial aspects, the factors that makes it imperative to majorly use the ICF in the disability classification of patients with migraine.

Studies about the functioning of patients with migraine are not a recent phenomenon. This review found articles dated from the year 1994. In addition, there exists several validated instruments to assess the disability measures and migraine impact in several aspects of a patients' life. Nevertheless, it was detected that identification was difficult from the study's results regarding the aspects of a patient's life that were more affected. ${ }^{14-16}$

\section{Body Functions}

In this component, it was found that the most-prevalent category of the studies of this scoping review was "b280 pain sensation", which confirms the presently known information about migraine, by considering pain as the main characteristic. ${ }^{17}$ It is therefore important to highlight, however, that migraine has, more and more, presented itself as a process not limited to pain sensation only. Corroborating this observation, other findings of this review clarifies that factors joined to body functions show alteration in migraineur's population. ${ }^{6}$

Despite this, the importance of this category is not diminished since the pain frequency remains the most important outcome in the assessment of this population for altering the life quality significantly and collaborating with other following outcomes. ${ }^{2,3,18}$ Furthermore, it was possible to confirm, in the present review, that the most-assessed outcomes in the studies of migraineurs' populations were related to pain sensation in the patient.
In "body functions", the second-most frequent category was "b 130 Functions of energy and impulses" that included issues such as motivation, appetite, desire, and impulse control. "1 There is a past study that demonstrated the relation between migraine and the functions of energy as well as the impulses when they demonstrate the thalamus involvement in the alterations caused by migraine in functions of food intake and anxiety control. 19,20

Furthermore, the outcome called vitality was included in this category. Thus, the number of articles that used the Medical Outcomes Short-Form Health Survey (SF-36), despite the existence of specific and validated questionnaires, increases the number of researchers that assessed this item. However, the patients' perception and the neuropathogenic explanation of migraine itself demonstrates that this category has relevance for a studied population, which makes its presence imperative in instruments that seek to assess or classify this population. ${ }^{19,21-31}$

In $17 \%$ of the articles included in this review, the outcomes related to the category "b5106 Regurgitation and Vomiting" were found. It is therefore important to detach that, in relation to qualitative studies, this category has been constantly indicated by patients, which leads us to believe that its impact in migraineurs' quality of lives remains underestimated by the studies now conducted with this population. ${ }^{32,33}$

Within the component Body Functions, is remains important to highlight that $15.6 \%$ of the included articles assessed the outcomes related to tolerance to physical exercise or to "sleep functions". Concerning physical exercises, the established relation in larger part of the studies found, reference to this issue of crises aggravation with the performance of physical exercises. ${ }^{21,34,35}$ However, it was not related to the cardiovascular system, as would be in the ICF category present in this component. Instead, some existing studies are researching beyond this question and have shown that, despite this established fact, the performance of physical exercises between the periods of crises have shown efficacy in the reduction of frequency and in the intensity of crises in patients with migraine. Therefore, it is important to further evaluate this point in order to clarify what intensity of migraine diminishes the tolerance to exercise with a differentiation of the periods without and with crises. ${ }^{36,37}$

Regarding sleep functions, a previous study ${ }^{35}$ demonstrated improvement in the sleep quality among treated patients with migraine, while another one ${ }^{38}$ established an important relationship among patients who presented 
migraine and reduction in the sleep quality and the risk of sleep apnea. This finding showed that, despite it not being possible to establish a relationship between the cause and effect, it has already been demonstrated that reduction in the sleep quality is twice as much prevalent in population with migraine as in the general population, which makes it important to detach that this is a prevalent condition in the classification of patients with migraine, both by established relation and by the impact that sleep quality has on quality of life of these patients. ${ }^{39}$

\section{Body Structures}

The outcomes to body structures found were inserted in the rank "s710 Structure of the region of the head and of the neck". It is therefore important to highlight that the included studies presented measurements that were more related to the region of the neck than to that of the head, despite the fact that a migraine is actually a headache. This phenomenon can be explained by the fact that migraine's impact on the head region is very established, while investigations are on about its impact on the neck region. ${ }^{40-42}$

A previous study assessed the shoulder region, and some other studies studied the connection of migraine and structures of the vertebral column and the impact of other body regions via peripheral sensitization. However, the small number of researches that have assessed these outcomes have shown that the major focus of research remains restricted to the region where the pain occurs. ${ }^{43}$

The allodynia questionnaire is a device that extrapolates this more local logic of assessment of patients with migraine and seeks, albeit in a generic way, to identify repercussions in other body regions. However, in this study, none of the included studies used this tool, which could have enlarged the number of categories listed in this component. ${ }^{44}$

\section{Activities and participation}

"Activities and participation" is one of the greatest legacies that the ICF brings to this population classification. The functioning and disability generated by this sickness are exactly related to the individual capacity of using a body (structures and functions) in contact with a determined environment to execute tasks (activities) inserted in a specific social context. ${ }^{11}$ This scoping review identified a large number of outcomes related to this component, which corroborated with the status of up-to-date art, in that this is a disabling disease with a high personal and social impact. ${ }^{1,45-47}$ The highest frequency among these categories was "d850 paid work." The economic aspect linked to this category enhances its importance, which explains it being the most frequent aspect in this component. It was also necessary to detach that this population profile strengthens this impact, since the major prevalence of the disease happens exactly, within the age group economically active. ${ }^{48,49}$

A paper on Brazilian population estimated that $>55 \%$ of its population with migraine works in Brazil, while $\geq 10 \%$ are unemployed and $20 \%$ are "housewives" or "students", so that almost $85 \%$ of the study population can be deemed to be potentially active..$^{50}$

In addition, absenteeism and decrease in productivity of people during migraine crises generate costs or income deficit both for themselves and for the market they are based in, what makes that, especially at this point, migraine becomes a disease of great impact, both at personal and social fronts. As a result, migraine can be considered as a public health problem. ${ }^{1,6,45}$

The second-most frequent category was "socializing". Here are included denouements related to social functions and socialization. Despite being generic, the idea they send to, shows the impact caused by migraine in the social life. ${ }^{21,31}$ Then, it becomes important to highlight that researchers should give greater attention to this rank and this should be further investigated to obtain more specific outcomes in the context of socialization of the population with migraine. Nevertheless, it was also possible to perceive the relation between migraine and the outcomes linked to the rank "activities of recreation and leisure," which revealed that restriction in these activities directly affects the quality of life of individuals with migraine.

Thus, it has become imperative that patients' assessment not only about this ailment has clinical repercussions, the professionals who take care of this population need to pay special attention to social factors affecting these individuals in the sense of understanding which aspects of their social life needs improvement as well as rethink the existing therapeutics to promote entanglement among clinical objectives and patient's demands. ${ }^{6,19}$

\section{Environmental Factors}

As consolidated previously in the literature, the influence of environmental factors, especially those concerning crises triggers in individuals with migraine. In this scope, the most frequently found outcomes in the articles included "e240 Light" and "e2500 Sound Intensity". Both of these papers 
were related to the characterization of samples in relation to photophobia and phonophobia. ${ }^{2}$

Past studies have demonstrated the relation of migraine with other triggering factors such as climate change and cigarette smoking ${ }^{51}$ and have also demonstrated the relationship of crises triggered by climate changes, which evidences the importance of being better evaluated in the relations of migraine with environmental factors in which individuals such as in the study population are included. ${ }^{32}$

Furthermore, another relevant aspect is that osmophobia (the fear of smell) is a characteristic that can be present in individuals with migraine (as described in ICDH-3), and this point has not received the same attention as photophobia and phonophobia, which explains the fact that there is a lack of studies in consideration of this particular outcome. ${ }^{2,52}$

Therefore this research identified two outcomes that have already been mentioned as important factors in the disability of the study population. However, this review also highlights the importance of further studies in this spectrum to enable the determination of the factors of major impact in this population so as to seek treatments with better results for offering them to affected individuals toward creating environments with major facilitators and no obstacles that generate limitations and restrictions.

\section{Articles with validated questionnaires}

The 59 articles included in this study used validated questionnaires for the study population and they are discussed in this special session because it is possible to measure in the impact generated by migraine in an individual's quality of life and disability. Nevertheless, these studies did not make explicit in which biopsychosocial aspects the said impact was observed.

From discussing these discoveries, two questions may be considered relevant: these articles corroborate with those reported in this review about the deep impact generated by migraine. It could be confirmed from the perception of the high scores found in this population through the questionnaires applied by the found studies.

Nevertheless, it is necessary to detach the importance of a better clarification of the aspects of a patient's life that have been more decisive in these final scores to adopt a better approach both in the research and in the clinical environment for generating a wider and more precise spectrum in the physical, emotional, and social environment of this population.

\section{Conclusions}

This review demonstrated that migraine generates disabilities related to all of the ICF components; revealed the outcomes linked to diverse categories of this classification; and also demonstrated that this impact is broad and affects all areas of an individual's life.

Moreover, this review helped recognize the importance of the previously validated tools for this study population and their contribution in the measurement of migraine's impact on an individual's quality of life and functioning. However, we believe that it is necessary to demonstrate, in a broader way, the aspects of patients' life that are more affected, both in their labor activities and leisure, inserted in their own social context. Thus, the ICF raises an interesting proposal to bridge this gap for its capability to explain the impacts generated by migraine over the functioning of the study population in a universal language.

Funding: The authors did not receive support from any organization for the submitted work.

Conflicts of interest/Competing interests: The authors don't have conflicts of interest to declare that are relevant to the content of this article.

Author contributions: HFS, DAO, collected the data and paper draft; MMMBB, SFS, AKLS, DW and AST, paper draft and carried out the review of the final version.
Hugo Feitosa
https://orcid.org/0000-0003-3247-5310
Débora Wanderley
https://orcid.org/0000-0002-9743-5101
Manuella Morais Monteiro Barbosa Barros
https://orcid.org/0000-0003-4245-7335
Suellen Freitas da Silva
https://orcid.org/0000-0001-8549-5230
Alyne Karine de Lima Santos
https://orcid.org/0000-0003-0845-0113
Angélica da Silva Tenório
https://orcid.org/0000-0002-7066-9047
Daniella Araújo de Oliveira
https://orcid.org/0000-0003-1 187-0223

\section{References}

1. Global, regional, and national burden of migraine and tension-type headache, 1990-2016: a systematic analysis for the Global Burden of Disease Study 2016. Lancet Neurol 2018;17(11):954-976 Doi:10.1016/ 
s1474-4422(18)30322-3

2. Olesen J. International Classification of Headache Disorders. Lancet Neurol 2018;17(5):396-397 Doi:10.1016/s1474-4422(18)30085-1

3. Banzi R, Cusi C, Randazzo C, Sterzi R, Tedesco D and Moja L. Selective serotonin reuptake inhibitors (SSRIs) and serotonin-norepinephrine reuptake inhibitors (SNRIs) for the prevention of migraine in adults. Cochrane Database Syst Rev 2015;4(4):Cd002919 Doi:10.1002/14651858.CD002919.pub3

4. Lucchesi C, Baldacci F, Cafalli M, Dini E, Giampietri L, Siciliano $G$ and Gori S. Fatigue, sleep-wake pattern, depressive and anxiety symptoms and body-mass index: analysis in a sample of episodic and chronic migraine patients. Neurol Sci 2016;37(6):987-989 Doi:10.1007/ s10072-016-2505-1

5. Bordini CA, Roesler C, Carvalho Dde S, Macedo $D D$, Piovesan É, Melhado EM, . . . Vincent MB. Recommendations for the treatment of migraine attacks - $a$ Brazilian consensus. Arq Neuropsiquiatr 2016;74(3):262271 Doi:10.1590/0004-282×2015021

6. Leonardi $M$, Raggi A, Grazzi L and D'Amico D. Disability, ICF biopsychosocial model and burden of migraine. J Headache Pain 2015;16(Suppl 1):A2 Doi:10.1186/1 129-2377-16-s1-a2

7. ZwartJA, Dyb G, HagenK, SvebakS, Stovner L and Holmen J. Analgesic overuse among subjects with headache, neck, and low-back pain. Neurology 2004;62(9):15401544 Doi: 10.1212/01.wnl.0000123262.96132.fc

8. Levac D, Colquhoun $\mathrm{H}$ and O'Brien KK. Scoping studies: advancing the methodology. Implement Sci 2010;5:69 Doi: 10.1 186/1748-5908-5-69

9. Mallidou AA, Atherton P, Chan L, Frisch N, Glegg S and Scarrow $G$. Protocol of a scoping review on knowledge translation competencies. Syst $\operatorname{Rev} 2017 ; 6(1): 93$ Doi:10.1186/s13643-017-0481-z

10. Davis K, Drey N and Gould D. What are scoping studies? A review of the nursing literature. Int J Nurs Stud 2009;46(10):1386-1400 Doi: 10.1016/i. ijnurstu.2009.02.010

11. Stucki $G$ and Cieza $A$. The International Classification of Functioning, Disability and Health (ICF) Core Sets for rheumatoid arthritis: a way to specify functioning. Ann Rheum Dis 2004;63 Suppl 2(Suppl 2):ii40-ii45 Doi:10.1136/ard.2004.028233

12. The International Classification of Headache Disorders: 2nd edition. Cephalalgia 2004;24 Suppl 1:9-160 Doi:10.1111/j.1468-2982.2003.00824.x

13. Olesen J. ICHD-3 beta is published. Use it immediately. Cephalalgia 2013;33(9):627-628 Doi: $10.1177 / 0333102413487610$

14. Passchier J, de Boo M, Quaak HZ and Brienen JA.
Health-related quality of life of chronic headache patients is predicted by the emotional component of their pain. Headache 1996;36(9):556-560 Doi:10.1046/i.15264610.1996.3609556.x

15. Rendas-Baum R, Yang M, Varon SF, Bloudek LM, DeGryse RE and Kosinski M. Validation of the Headache Impact Test (HIT-6) in patients with chronic migraine. Health Qual Life Outcomes 2014;12:117 Doi:10.1186/ s12955-014-0117-0

16. Stewart WF, Lipton RB, Kolodner KB, Sawyer J, Lee C and Liberman JN. Validity of the Migraine Disability Assessment (MIDAS) score in comparison to a diarybased measure in a population sample of migraine sufferers. Pain 2000;88(1):41-52 Doi:10.1016/s03043959(00)00305-5

17. Silberstein SD. Practice parameter: evidence-based guidelines for migraine headache (an evidence-based review): report of the Quality Standards Subcommittee of the American Academy of Neurology. Neurology 2000;55(6):754-762 Doi:10.1212/wnl.55.6.754

18. Lillis J, Graham Thomas J, Seng EK, Lipton RB, Pavlović JM, Rathier L, . . Bond DS. Importance of Pain Acceptance in Relation to Headache Disability and Pain Interference in Women With Migraine and Overweight/Obesity. Headache 2017;57(5):709-718 Doi:10.1111/ head. 13058

19. Puledda F, Messina R and Goadsby PJ. An update on migraine: current understanding and future directions. J Neurol 2017;264(9):2031-2039 Doi:10.1007/ s00415-017-8434-y

20. Noseda R, Kainz V, Borsook D and Burstein R. Neurochemical pathways that converge on thalamic trigeminovascular neurons: potential substrate for modulation of migraine by sleep, food intake, stress and anxiety. PloS One 2014;9(8):e103929 Doi:10.1371/ journal.pone.0103929

21. Bigal ME, Bigal JO, Bordini CA and Speciali JG. Prevalence and costs of headaches for the public health system in a town in the interior of the state of São Paulo. Arq Neuropsiquiatr 2001;59(3-a):504-51 1 Doi:10.1590/s0004-282×2001000400005

22. Burk CT, Gilderman A, Salas J, Berenbeim D and Nichol MB. The impact of an over-the-counter migraine medication program on quality of life. Headache 2003;43(3):191-201 Doi:10.1046/i.15264610.2003.03042.x

23. Cohen JA, Beall DG, Miller DW, Beck A, Pait $G$ and Clements BD. Subcutaneous sumatriptan for the treatment of migraine: humanistic, economic, and clinical consequences. Fam Med 1996;28(3):171-177

24. Dartigues JF, Michel P, Lindoulsi A, Dubroca B and Henry $P$. Comparative view of the socioeconomic impact of 
migraine versus low back pain. Cephalalgia 1998; 18 Suppl 21:26-29 Doi:10.1177/0333102498018s2107

25. Durham CF, Alden KR, Dalton JA, Carlson J, Miller DW, Englebardt SP and Neelon VJ. Quality of life and productivity in nurses reporting migraine. Headache 1998;38(6):427-435 Doi:10.1046/j.15264610.1998.3806427.x

26. Elkind AH, O'Carroll P, Blumenfeld A, DeGryse R and Dimitrova R. A series of three sequential, randomized, controlled studies of repeated treatments with botulinum toxin type A for migraine prophylaxis. J Pain 2006;7(10):688-696 Doi:10.1016/i. ipain.2006.03.002

27. Ferro EC, Biagini AP, da Silva Í E, Silva ML and Silva $J R$. The combined effect of acupuncture and Tanacetum parthenium on quality of life in women with headache: randomised study. Acupunct Med 2012;30(4):252-257 Doi:10.1136/acupmed-2012-010195

28. Lipton RB, Liberman JN, Kolodner KB, Bigal ME, Dowson A and StewartWF. Migraine headache disability and healthrelated quality-of-life: a population-based case-control study from England. Cephalalgia 2003;23(6):441-450 Doi:10.1046/j.1468-2982.2003.00546.x

29. Michel P, Dartigues JF, Lindoulsi A and Henry P. Loss of productivity and quality of life in migraine sufferers among French workers: results from the GAZEL cohort. Headache 1997;37(2):71-78 Doi:10.1046/i.15264610.1997.3702071.x

30. Osterhaus JT, Townsend R, Gandek B and Ware JE, Jr. Measuring the functional status and well-being of patients with migraine headache. Headache 1994;34(6):337343 Doi:10.1111/i.1526-4610.1994.hed3406337.x

31. Mahmoudzadeh Zarandi F, Raiesifar A and Ebadi A. The Effect of Orem's Self-Care Model on Quality of Life in Patients with Migraine: a Randomized Clinical Trial. Acta Med Iran 2016;54(3):159-164

32. Moloney MF, Strickland OL, DeRossett SE, Melby MK and Dietrich AS. The experiences of midlife women with migraines. J Nurs Scholarsh 2006;38(3):278-285 Doi:10.1111/j.1547-5069.2006.00114.x

33. Scaratti C, Covelli V, Guastafierro E, Leonardi $M$, Grazzi L, Rizzoli PB, . . . Raggi A. A Qualitative Study On Patients With Chronic Migraine With Medication Overuse Headache: Comparing Frequent And NonFrequent Relapsers. Headache 2018;58(9):1373-1388 Doi: 10.1111 /head. 13385

34. Nazari F, Safavi M and Mahmudi M. Migraine and its relation with lifestyle in women. Pain Pract 2010;10(3):228234 Doi: $10.1111 /$ j.1533-2500.2009.00343.x

35. Shrivastava R, Pechadre JC and John GW. Tanacetum parthenium and Salix alba (Mig-RL) combination in migraine prophylaxis: a prospective, open-label study. Clin Drug Investig 2006;26(5):287-296 Doi: 10.2165/00044011-200626050-00006

36. Irby MB, Bond DS, Lipton RB, Nicklas B, Houle $T T$ and Penzien DB. Aerobic Exercise for Reducing Migraine Burden: Mechanisms, Markers, and Models of Change Processes. Headache 2016;56(2):357-369 Doi: 10.1111 /head. 12738

37. Krøll LS, Sjödahl Hammarlund C, Gard G, Jensen RH and Bendtsen $L$. Has aerobic exercise effect on pain perception in persons with migraine and coexisting tension-type headache and neck pain? A randomized, controlled, clinical trial. Eur J Pain 2018;Doi: 10.1002/ ejp. 1228

38. Buse DC, Rains JC, Pavlovic JM, Fanning KM, Reed ML, Manack Adams A and Lipton RB. Sleep Disorders Among People With Migraine: Results From the Chronic Migraine Epidemiology and Outcomes (CaMEO) Study. Headache 2019;59(1):32-45 Doi: 10.1111/head.13435

39. Zhu B, Dong Y, Xu Z, Gompf HS, Ward SA, Xue Z, . . . Xie Z. Sleep disturbance induces neuroinflammation and impairment of learning and memory. Neurobiol Dis 2012;48(3):348-355 Doi: 10.1016/i. nbd.2012.06.022

40. Ferracini GN, Chaves TC, Dach F, Bevilaqua-Grossi D, Fernández-de-Las-Peñas $C$ and Speciali JG. Relationship Between Active Trigger Points and Head/ Neck Posture in Patients with Migraine. Am J Phys Med Rehabil 2016;95(11):831-839 Doi: 10.1097/ phm.0000000000000510

41. Ferracini GN, Florencio LL, Dach F, Chaves TC, PalaciosCeña $M$, Fernández-de-Las-Peñas $C, \ldots$ Speciali JG. Myofascial Trigger Points and Migraine-related Disability in Women With Episodic and Chronic Migraine. Clin J Pain 2017;33(2):109-115 Doi: 10.1097/ aip.0000000000000387

42. Özer $G$ and Benlier N. Neck pain: is it part of a migraine attack or a trigger before a migraine attack? Acta Neurol Belg 2020;120(2):289-293 Doi:10.1007/ s13760-018-1030-9

43. Gonçalves MC, Chaves TC, Florencio LL, Carvalho GF, Dach F, Fernández-De-Las-Penãs $C$ and BevilaquaGrossi $D$. Is pressure pain sensitivity over the cervical musculature associated with neck disability in individuals with migraine? J Bodyw Mov Ther 2015;19(1):67-71 Doi:10.1016/i.jbmt.2014.02.007

44. Florencio LL. Adaptação transcultural e confiabilidade do questionário 12 item Allodynia Symptom Checklist para o Brasil. Ribeirão Preto: Universidade de São Paulo; 2013.

45. Steiner TJ, Stovner $L$ and Birbeck GL. Migraine: the seventh disabler. J Headache Pain 2013;14(1):1 Doi: 10.1186/11 29-2377-14-1 
46. Bigal ME, Serrano D, Reed $M$ and Lipton RB. Chronic migraine in the population: burden, diagnosis, and satisfaction with treatment. Neurology 2008;71(8):559566 Doi:10.1212/01.wnl.0000323925.29520.e7

47. Steiner TJ, Stovner L, Katsarava Z, Lainez JM, Lampl C, Lantéri-Minet $M, \ldots$ Andrée $C$. The impact of headache in Europe: principal results of the Eurolight project. J Headache Pain 2014;15(1):31 Doi:10.1 186/1129-2377-15-31

48. Santos AKL, Feitosa $H$, Silva SF, Barros MMMB, Ferro JKDO, Souza AISDO, . . . Oliveira DAD. Functionality changes of migraine women. Headache Med 2018; 183189 Doi:10.48208/headachemed.2018.20

49. Queiroz LP, Peres MF, Piovesan EJ, Kowacs F, Ciciarelli MC, Souza JA and Zukerman E. A nationwide population-based study ofmigraineinBrazil.Cephalalgia2009;29(6):642-649
Doi:10.1111/j.1468-2982.2008.01782.x

50. Peres MFP, Queiroz LP, Rocha-Filho PS, Sarmento EM, Katsarava $Z$ and Steiner TJ. Migraine: a major debilitating chronic non-communicable disease in Brazil, evidence from two national surveys. I Headache Pain 2019;20(1):85 Doi:10.1186/s10194-019-1036-6

51. Ozdemir G, Aygül R, Demir R, Ozel L, Ertekin A and Ulvi $H$. Migraine prevalence, disability, and sociodemographic properties in the eastern region of Turkey: a population-based door-to-door survey. Turk J Med Sci 2014;44(4):624-629

52. Chitsaz A, Ghorbani A, Dashti M, Khosravi M and Kianmehr M. The Prevalence of Osmophobia in Migranous and Episodic Tension Type Headaches. Adv Biomed Res 2017;6:44 Doi:10.4103/2277-9175.204587 